\title{
Vaccination Uncertainties and COVID-19 Prospects in 2021
}

\author{
Peng Wu $\mathrm{W}^{1,2, *} ;$ Benjamin J. Cowling ${ }^{1,2} ;$ Gabriel M. Leung ${ }^{1,2}$
}

As we pass the first anniversary of the World Health Organization's (WHO) declaration of a Public Health Emergency of International Concern (1), we look back at the impact of coronavirus disease 2019 (COVID19) in 2020 and the prospects for the pandemic in 2021.

The almost inverse correlation between preCOVID-19 assessed preparedness (2) and actual performance (3) one year since the world first learned of the pandemic potential of the COVID-19 virus (4) is a stark reminder of Robert Burns's "The best laid schemes o' Mice an' Men / Gang aft agley." Going forward, we clearly need to bridge this disconnect and identify reliable indicators of true preparedness that are widely applicable and can stand the test of a real outbreak.

In the past year we have observed unprecedented public health and social measures (PHSMs) including lockdowns and travel restrictions (5). The health impact could have been much larger without these sustained drastic interventions, but the societal and economic cost has still not yet been fully realized. Although affected earliest in the pandemic, the rapid implementation of effective measures in China resulted in domestic elimination of infections by March 2020 (G) with only very occasional case clusters observed thereafter, leading to one of the lowest rates of infection per capita worldwide ( 7 ) and without the need for sustained PHSMs since.

COVID-19 vaccines are eagerly anticipated to bring an "end" to the pandemic, although the virus may continue to circulate and is likely to cause seasonal epidemics in the post-vaccination era (8). We must be vigilant for the emergence of new variants, especially those arising from convergent evolution, that are more transmissible, virulent, or could escape vaccine immunity. As administration of COVID-19 vaccinations is rolled out in more countries, we should begin to see reductions in case numbers and hospitalizations, and the opportunity to relax some PHSMs that have been in place for much of the past year. However, with delays in vaccine availability and fatigue with physical distancing measures, we are concerned that there could be more COVID-19 deaths in 2021 than 2020. With a resurgence in case numbers in many parts of the world, we urgently need to vaccinate older adults, other target groups such as healthcare workers and front-line workers in essential services and ultimately the whole adult population.

If high vaccination coverage is achieved and vaccines have high effectiveness against infection, we should see herd immunity preventing large epidemics although smaller outbreaks would remain a risk. On the other hand, even if coverage of a vaccine with insufficiently high efficacy reaches high levels, herd immunity will be difficult to achieve. In China, vaccination efforts have so far focused on high-risk working populations (9), leaving older adults vulnerable to infection if outbreaks recur. However, if vaccination coverage does not reach high levels, or if the vaccines prevent disease development but not infections (10) and specifically do not limit transmission, a more concerning scenario may play out where PHSMs need to be maintained for much longer to protect healthcare systems against surges in cases. Achieving high vaccine coverage will be hindered by vaccine hesitancy (11), which can be a particular problem with novel vaccines against a coronavirus that are licensed under emergency approvals with a rapid development timeline.

While we are encouraged by the successes of several promising vaccines with high efficacy against symptomatic disease in interim analyses of phase 3 trials, others have unsurprisingly been reporting more variable data. Even amongst those that have already been approved for emergency rollout, studies addressing extended use in population subgroups (e.g. the extremes of age, immunocompromised groups, and pregnant mothers), the optimal dosing interval between prime and booster, head-to-head comparisons between vaccines, and possible mixed use of vaccines between different technology platforms as first or second booster are ongoing. Therefore, many uncertainties remain as the pandemic threat 
necessitates immediate vaccine deployment. Postmarketing pharmacovigilance and safety monitoring, as well as vaccine effectiveness studies, will help us further finetune immunization strategies.

As such, openness and transparency are the only sure way of countering vaccine hesitancy. Full and systematic disclosure of data from clinical trials and post-rollout empirical studies is needed to determine the safety and efficacy of each vaccine for different population groups, preferably in the international peer reviewed literature in parallel with regulatory submissions at the national level.

It is expected that the protection from vaccination against COVID-19 would not be lifelong, although data on waning of the neutralizing antibody after vaccination have been mixed (12-13). It is worrying to see a surge of COVID-19 cases in countries with high attack rates in their first waves (14-15). Revaccination may be needed sooner or later to prevent vaccinated or infected individuals from reinfection, although development of new vaccines would become essential if new virus variants emerge capable of escaping from vaccine-induced immune protection (16).

Despite the uncertainties in efficacy and safety, vaccines are expected to be the single most effective intervention to bring the COVID-19 pandemic to a resolution. To achieve fair and equitable access to vaccines, ethical principles should be upheld to overcome vaccination nationalism and, at the same time, to guarantee efficient access for individuals/countries in greater need (17-18). The moral imperative for equitable access to vaccines ultimately also serves the utilitarian purpose of selfprotection by vaccinating others.

Funding: The Health and Medical Research Fund, Food and Health Bureau, Government of the Hong Kong Special Administrative Region (grant no. COVID190118). BJC and GML are supported by the AIR@innoHK program of Hong Kong SAR Government.

Conflicts of Intrest: BJC consults for Roche and Sanofi Pasteur. The authors report no other potential conflicts of interest.

doi: $10.46234 / \mathrm{ccdcw} 2021.044$

\# Corresponding author: Peng Wu, pengwu@hku.hk.

\footnotetext{
${ }^{1}$ WHO Collaborating Centre for Infectious Disease Epidemiology and Control, School of Public Health, LKS Faculty of Medicine, The University of Hong Kong, Hong Kong, China; ${ }^{2}$ Laboratory of Data Discovery for Health, Hong Kong Science and Technology Park, Hong Kong, China.
}

Submitted: January 27, 2021; Accepted: January 31, 2021

\section{REFERENCES}

1. World Health Organization. Statement on the second meeting of the International Health Regulations (2005) Emergency Committee regarding the outbreak of novel coronavirus (2019-nCoV). https://www. who.int/news/item/30-01-2020-statement-on-the-second-meeting-ofthe-international-health-regulations-(2005)-emergency-committeeregarding-the-outbreak-of-novel-coronavirus-(2019-nCoV). [2021-1-25].

2. GHS Index-Global Health Security Index: Building Collective Action and Accountability. Nuclear Threat Initiative and Johns Hopkins Bloomberg School of Public Health, 2019. https://www.ghsindex.org/. [2021-1-25].

3. Center for Systems Science and Engineering, Johns Hopkins University. COVID-19 dashboard. https://coronavirus.jhu.edu/map.html. [2021$1-25]$.

4. Wu JT, Leung K, Leung GM. Nowcasting and forecasting the potential domestic and international spread of the 2019-nCoV outbreak originating in Wuhan, China: a modelling study. Lancet 2020;395(10225):689 - 97. http://dx.doi.org/10.1016/S0140-6736(20) 30260-9.

5. World Health Organization. WHO coronavirus disease (COVID-19) dashboard. https://covid19.who.int/. [2021-1-25].

6. Leung K, Wu JT, Liu D, Leung GM. First-wave COVID-19 transmissibility and severity in China outside Hubei after control measures, and second-wave scenario planning: a modelling impact assessment. Lancet 2020;395(10233):1382 - 93. http://dx.doi.org/10. 1016/S0140-6736(20)30746-7.

7. World Health Organization. WHO coronavirus disease (COVID-19) dashboard: situation by country, territory $\&$ area. https://covid19. who.int/table. [2021-1-25].

8. Kissler SM, Tedijanto C, Goldstein E, Grad YH, Lipsitch M. Projecting the transmission dynamics of SARS-CoV-2 through the postpandemic period. Science 2020;368(6493):860 - 8. http://dx.doi.org/10.1126/ science.abb5793.

9. Chinese Center for Disease Control and Prevention. COVID-19 vaccine Q\&A http://www.chinacdc.cn/jkzt/crb/zl/szkb_11803/jszl_ 12208/202101/t20210107_223665.html. [2021-1-25]. (In Chinese).

10. Peiris M, Leung GM. What can we expect from first-generation COVID-19 vaccines? Lancet 2020;396(10261):1467 - 9 . http://dx.doi.org/10.1016/S0140-6736(20)31976-0.

11. Murphy J, Vallières F, Bentall RP, Shevlin M, McBride O, Hartman TK, et al. Psychological characteristics associated with COVID-19 vaccine hesitancy and resistance in Ireland and the United Kingdom. Nat Commun 2021;12(1):29. http://dx.doi.org/10.1038/s41467-02020226-9.

12. Wajnberg A, Amanat F, Firpo A, Altman DR, Bailey MJ, Mansour M, et al. Robust neutralizing antibodies to SARS-CoV-2 infection persist for months. Science 2020;370(6521):1227 - 30. http://dx.doi.org/10. $1126 /$ science.abd7728

13. Seow J, Graham C, Merrick B, Acors S, Pickering S, Steel KJA, et al. Longitudinal observation and decline of neutralizing antibody responses in the three months following SARS-CoV-2 infection in humans. Nat Microbiol 2020;5(12):1598 - 607. http://dx.doi.org/10.1038/s41564020-00813-8.

14. Buss LF, Prete CA Jr, Abrahim CMM, Mendrone A Jr, Salomon T, de Almeida-Neto C, et al. Three-quarters attack rate of SARS-CoV-2 in the Brazilian Amazon during a largely unmitigated epidemic. Science 2021;371(6526):288 - 92. http://dx.doi.org/10.1126/science.abe9728.

15. Naveca F, Da Costa C, Nascimento V, Souza V, Corado A, Nascimento F, et al. SARS-CoV-2 reinfection by the new Variant of Concern (VOC) P.1 in Amazonas, Brazil. https://virological.org/t/sars-cov-2reinfection-by-the-new-variant-of-concern-voc-p-1-in-amazonasbrazil/596. [2021-1-25].

16. Wibmer CK, Ayres F, Hermanus T, Madzivhandila M, Kgagudi P, Lambson BE, et al. SARS-CoV-2 501Y.V2 escapes neutralization by 
South African COVID-19 donor plasma. bioRxiv 2021 http://dx.doi.org/10.1101/2021.01.18.427166.

17. National Academies of Sciences, Engineering, and Medicine. Framework for equitable allocation of COVID-19 vaccine. Washington, DC: The National Academies Press. 2021. http://dx.doi. org/10.17226/25917.

18. Herzog LM, Norheim OF, Emanuel EJ, McCoy MS. Covax must go beyond proportional allocation of covid vaccines to ensure fair and equitable access. BMJ 2021;372:m4853. http://dx.doi.org/10.1136/ bmj.m4853.

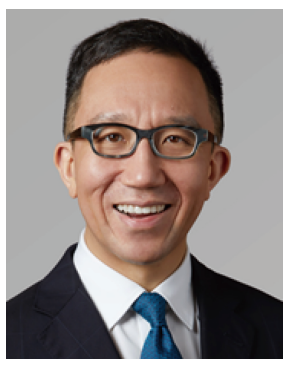

Gabriel M. Leung, MD, MPH

Helen and Francis Zimmern Professor in Population Health

Dean of Medicine, The University of Hong Kong

Chief Scientific Officer, Laboratory of Data Discovery for Health, Hong Kong Science and Technology Park, Hong Kong, China 